\title{
Editorial
}

Frédéric Marçon*

\section{Paediatric Needs: Challenge and Opportunities for Hospital Pharmacists}

https://doi.org/10.1515/pthp-2018-0016

In the early 2000s, the European Medicines Agency (EMA) and the United States Food and Drug Administration (US-FDA) both highlighted the lack of paediatric drug development and developed incentive policies to try to fill this gap. For instance, during the 2006 - 2015 period, the EMA developed an inventory of more than 350 active substances corresponding to paediatric needs [1]. In parallel, US-FDA also established its own list of paediatric drug development priorities [2]. However, despite the EMA paediatric-use marketing authorisation (PUMA), the US-FDA best pharmaceuticals for children act (BPCA) and the US-FDA paediatric research equity act (PREA) incentive regulations, many old drugs commonly used in paediatric therapy still lack age-appropriate formulations or pharmacokinetic, efficacy and safety data supporting their use [3]. About one-fifth $(n=80 / 353)$ of the 355 "paediatric needs" listed by the EMA concerned active substances belonging to the WHO list of essential medicines for children (regardless of the indication) and about one-half $(n=196 / 353)$ mentioned the need for an age-appropriate formulation (regardless of the route of administration).

Prescribing off-label or unlicensed drugs is a common practice in hospital with varying rates according to the patient's age and the prescribing physician's specialty [4]. Published clinical studies often justify the use of an active substance on the basis of a demonstrated benefit/risk ratio in a specific population. However, it must be remembered that off-label use and use of unlicensed or age-inappropriate drugs has also been reported to be detrimental [5]. The paediatric population comprises several age groups (i. e. neonates, infants, children and adolescents) that account for pharmacokinetic and pharmacodynamics variability, which must always be considered when interpreting the results of clinical studies. The use of extemporaneously

*Corresponding author: Frédéric Marçon, Pharmacie à Usage Intérieur, Groupe de Recherche en Pharmacotechnie Pédiatrique (GREPP), CHU d'Amiens, Avenue René Laënnec, Salouël, France, E-mail: marcon.frederic@chu-amiens.fr compounded and non-standardised drugs may also be responsible for between-subject or between-study pharmacological variability depending on the Biopharmaceutical Classification System (BCS) class of the active substance. For instance, crushed tablets, suspension or solution of the same BCS class II active substance will probably neither have the same pharmacokinetics nor the same efficacy [6]. Hospital pharmacists may therefore play a key role in providing quality standardised drugs to treat paediatric patients - the first step to improve the quality of pharmaceutical care - and studying their pharmacokinetics, efficacy and safety. In the present issue, two articles address optimisation of the treatment of eosinophilic oesophagitis with a budesonide suspension or solution. It is noteworthy that some clinical studies reporting the efficacy of budesonide have confused the sucralose excipient with the food grade sweetener Splenda ${ }^{\mathrm{TM}}$ (1\% sucralose in maltodextrins), which may lead to over-exposure of children to sucralose and loss of the viscosity property due to the absence of maltodextrins. This illustrates the need for a full description, standardisation and study of formulas to clearly establish a reference formula and obtain comparable results during clinical studies and uses.

Designing an age-appropriate dosage form is not a simple process, as palatability and stability probably remain the most challenging issues for hospital pharmacists. Liquid oral forms may be preferred to solid oral forms to facilitate accurate administration of a dose to patients with widely varying ages and weights, especially suspensions and solutions (with advantages and disadvantages for both forms). A quality-by-design approach is usually chosen to carefully select excipients and limit their number according to "Keep It Safe and Simple" (KISS) compounding. This is particularly true for paediatric formulations in view of the toxicity of certain excipients in this population [7]. In this issue, a dexamethasone suspension and a fluconazole suspensions were designed by means of this approach with special focus on avoiding exposure of children to commercial products that use harmful (e. g. ethanol) or potentially harmful excipients (e.g. parahydroxybenzoate), illustrating the major role played by hospital pharmacists in the selection of the 
safest excipients. You will also find in this issue an opinion paper dealing with the development and the preparation of suspension that reports the main challenges facing the hospital pharmacist in designing ageappropriate suspensions.

Both active ingredient and degradation product contents should be considered when performing stability testing and shelf-life determination. The International Conference on Harmonization (ICH Q3B) describes specific levels of degradants (or process impurities) generally allowed based on maximum daily dose of active substance administered. Jean Vigneron has already stressed the role of hospital pharmacists in conducting this type of study in a special issue of Pharmaceutical Technology in Hospital Pharmacy [8]. The final specifications must therefore be clearly established to ensure the safety, identity, strength, performance, and quality of standardised drugs.

Disseminating research findings and transmitting the know-how of these age-appropriate unlicensed drugs is therefore essential to improve the pharmaceutical care of our patients. For instance, the needs for an ageappropriate formulation of prednisone and clonidine identified by EMA have been addressed in this special issue and can now be used by hospital pharmacists. Likewise, many formulas have been reported in the literature, compiled in books [9] and compiled in specialist websites such as Stabilis ${ }^{\circledR}$ [10] to help hospital pharmacists provide the best "state-of-the-art" pharmaceutical care. Unfortunately, few studies have also focused on the efficacy, safety or pharmacokinetics of these unlicensed drugs and hospital pharmacists should work to fill this gap.

Finally, the possibility of collaboration between the pharmaceutical industry and teaching hospitals for drug development may be a solution to transform the almost orphan status of paediatric drug therapy and may also represent an interesting way of self-financing institutional research. We have the "know-how", we must provide patients with "state-of-the-art" treatment and we can promote investigational research - the ball may be in our court.

\section{References}

1. European Medicines Agency. Needs for paediatric medicines [Internet]. Available from: http://www.ema.europa.eu/ema/ index.jsp?curl=pages/regulation/document_listing/docu ment_listing_000096.jsp. Accessed: 28 Mar 2018.

2. National Institutes of Health. Best pharmaceuticals for children act (BPCA) priority list of needs in pediatric therapeutics [Internet]. 2017. p. 19. Available from: https://bpca.nichd.nih. gov/prioritization/status/Documents/priority_list_063017.pdf. Accessed: 28 Feb 2018.

3. Wimmer S, Rascher W, McCarthy S, Neubert A. The EU paediatric regulation: still a large discrepancy between therapeutic needs and approved paediatric investigation plans. Pediatr Drugs 2014;16:397-406.

4. Cuzzolin L, Zaccaron A, Fanos V. Unlicensed and off-label uses of drugs in paediatrics: a review of the literature. Fundam Clin Pharmacol 2003;17:125-31.

5. Kaguelidou F, Beau-Salinas F, Jonville-Bera AP, Jacqz-Aigrain E. Neonatal adverse drug reactions: an analysis of reports to the French pharmacovigilance database. Br J Clin Pharmacol 2016;82:1058-68.

6. Amidon GL, Lennernäs H, Shah VP, Crison JR. A theoretical basis for a biopharmaceutic drug classification: the correlation of in vitro drug product dissolution and in vivo bioavailability. Pharm Res 1995;12:413-20.

7. Salunke S, Giacoia G, Tuleu C. The STEP (safety and toxicity of excipients for paediatrics) database. Part 1-A need assessment study. Int J Pharm 2012;435:101-11.

8. Vigneron J. Stability studies: a scientific mission of the hospital pharmacist. Pharm Technol Hosp Pharm 2017;2:143-44.

9. Trissel LA. American pharmacists association. Trissel's stability of compounded formulations. Washington, DC: American Pharmacists Association, 2012.

10. Vigneron J, Rota J-B Stabilis [Internet]. 2017 Available from: http://www.stabilis.org/. Accessed: 30 Dec 2017. 